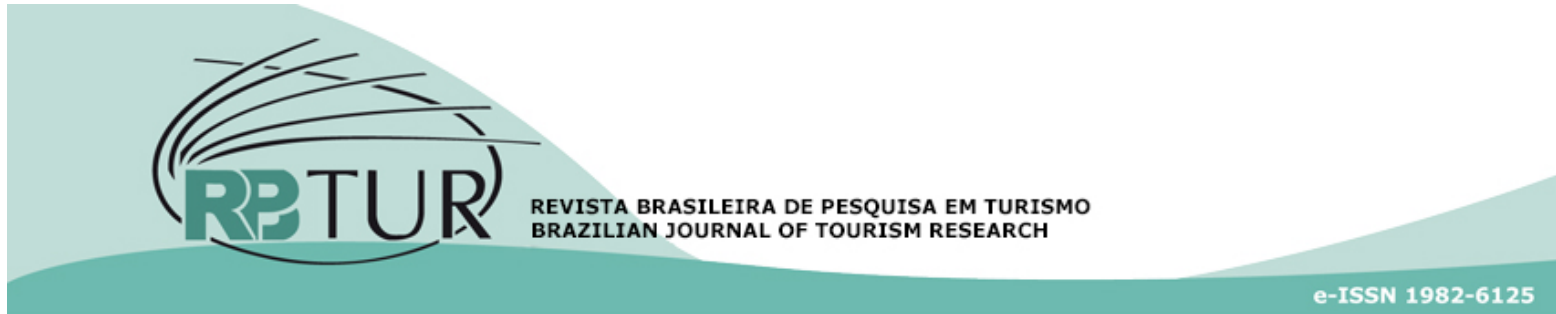

\title{
Artigos
}

\section{Avaliação do Potencial Geoturístico do Parque Estadual Serra do Rola Moça/MG}

\author{
Evaluation of the Geotourism Potential of the Serra do Rola Moça State \\ Park/MG
}

\section{Evaluación del Potencial Geoturístico del Parque Estatal Serra do Rola Moça/MG}

\section{Dayane Letícia Rodrigues dos Reis ${ }^{1}$}

1 Universidade Federal de Minas Gerais (UFMG), Belo Horizonte, MG, Brasil.

\begin{tabular}{|c|c|}
\hline & Resumo \\
\hline $\begin{array}{l}\text { Palavras-chave: } \\
\text { Geodiversidade. } \\
\text { Geoturismo. } \\
\text { Parque Estadual Serra do Rola Moça. }\end{array}$ & $\begin{array}{l}\text { A geodiversidade é bastante visada pelo turismo e, neste sentido, o geoturismo evidencia os } \\
\text { aspectos e promove a divulgação do meio abiótico em uma linguagem acessível ao publico } \\
\text { leigo. Diante do potencial de uso da geodiversidade, é necessário que se estabeleçam medidas } \\
\text { de planejamento para sua utilização sustentável. Sendo assim, o presente artigo tem como } \\
\text { objetivo geral identificar geossítios localizados no Parque Estadual Serra do Rola Moça } \\
\text { (PESRM), Minas Gerais, realizando avaliação quantitativa e do risco de degradação com ênfase } \\
\text { no uso turístico. Os procedimentos metodológicos utilizados foram pesquisa bibliográfica e le- } \\
\text { vantamento de dados em campo. Para a quantificação dos geossítios foi adaptada à metodo- } \\
\text { logia proposta por Brilha (2015), ou seja, foram realizadas mudanças em alguns dos critérios } \\
\text { sugeridos pelo autor, levando em consideração a realidade da área de estudo. A partir da iden- } \\
\text { tificação e quantificação dos geossítios foi evidenciado que o geoturismo pode ser desenvol- } \\
\text { vido no PESRM, embora se tenha identificado algumas deficiências na infraestrutura dos ge- } \\
\text { ossítios. Dessa forma, acredita-se que o desenvolvimento de atividades geoturísticas irá con- } \\
\text { tribuir para o conhecimento e conservação da geodiversidade local, mas para isso é necessário } \\
\text { à elaboração de estratégias que envolvam os gestores do PESRM, a comunidade local e aca- } \\
\text { dêmica. }\end{array}$ \\
\hline
\end{tabular}

Abstract

\section{Keywords:}

Geodiversity.

Geotourism.

Serra do Rola Moça State Park.
Geodiversity is highly regarded by tourism and, in this sense, geotourism highlights the aspects and promotes the dissemination of the abiotic environment in a language accessible to the lay public. Faced with the potential of using geodiversity, it is necessary to establish planning measures for its sustainable use. Thus, the present article has the general objective of identifying geosites located in the Serra do Rola Moça State Park, Minas Gerais, performing a quantitative evaluation and risk of degradation with an emphasis on tourism use. The methodological procedures used were bibliographic research and data collection in the field. For the quantification of the geosites it was adapted to the methodology proposed by Brilha (2015), that is, changes were made in some of the criteria suggested by the author, taking into account the reality of the study area. From the identification and quantification of the geosites it was evidenced that the geotourism can be developed in the Serra do Rola Moça State Park, although some deficiencies in the infrastructure of the geosites have been identified. Thus, it is believed that the development of geotourism activities will contribute to the knowledge and conservation of the local geodiversity, but for this it is necessary to elaborate strategies that involve the managers, the local community and academic. 


\section{Resumen}

\section{Palabras clave:}

Geodiversidad Geoturismo.

Parque Estatal Serra do Rola Moça.
La geodiversidad es bastante visada por el turismo y, en este sentido, el geoturismo evidencia los aspectos y promueve la divulgación del medio abiótico en un lenguaje accesible al publico laico. Ante el potencial de uso de la geodiversidad, es necesario que se establezcan medidas de planificación para su utilización sostenible. Por lo tanto, el presente artículo tiene como objetivo general identificar geosítios localizados en el Parque Estatal Serra do Rola Moça (PESRM), Minas Gerais, realizando evaluación cuantitativa y del riesgo de degradación con énfasis en el uso turístico. Los procedimientos metodológicos utilizados fueron investigación bibliográfica y levantamiento de datos en campo. Para la cuantificación de los geosítios fue adaptada a la metodología propuesta por Brilha (2015), o sea, se realizaron cambios en algunos de los criterios sugeridos por el autor, teniendo en cuenta la realidad del área de estudio. A partir de la identificación y cuantificación de los geosítios se evidenció que el geoturismo puede ser desarrollado en la PESRM, aunque se han identificado algunas deficiencias en la infraestructura de los geosítios. De esta forma, se cree que el desarrollo de actividades geoturísticas contribuirá al conocimiento y conservación de la geodiversidad local, pero para ello es necesario la elaboración de estrategias que involucren a los gestores del PESRM, la comunidad local y académica.

Como citar: Reis, D.L. R. (2019). Avaliação do Potencial Geoturístico do Parque Estadual Serra do Rola Moça/MG. Revista Brasileira de Pesquisa em Turismo, São Paulo, 13 (1), p.

92-107, jan./abr. http://dx.doi.org/10.7784/rbtur.v13i1.1482
Revisado por pares.

Recebido em: 12/07/2018.

Aprovado em: 16/11/2018.

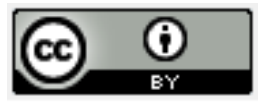

\section{INTRODUÇÃO}

A geodiversidade, compreendida como o conjunto dos elementos abióticos do meio natural, é a base estrutural do planeta, pois fornece materiais essenciais para a sustentação da vida e evolução das espécies. De modo geral, pode-se afirmar que a biodiversidade está diretamente condicionada a se fixar e desenvolver na diversidade dos ambientes abióticos (Bruschi, 2007). Nesse sentido, a geodiversidade e a biodiversidade guardam complexas relações entre si e são complementares para uma compreensão holística do meio natural (Santos, 2017). Sendo assim, alguns estudiosos têm buscado produzir e difundir conhecimentos sobre a geodiversidade, propondo métodos para sua valorização e conservação.

Dessa forma, quando são atribuídos valores à geodiversidade, possibilitamos que certas regiões apresentem grande importância seja do ponto de vista econômico, científico, didático ou turístico, e tais valores, permitem que essas regiões venham a ser inventariadas e quantificadas como geossítios. 0 conjunto desses geossítios constitui o patrimônio geológico (Brilha, 2005).

Ao longo do tempo, diversos termos e definições foram determinados para conceituar o que são e como se chamam os locais que integram o patrimônio geológico. Os termos que vêm sendo utilizados são: geolugar, geotopo, ponto de interesse geológico (PIG), local de interesse geológico (LIG) e geossítios. Independentemente da denominação, estes locais se destacam por seu valor que pode ser científico, educativo, turístico ou outros (Romão \& Garcia, 2017). Neste artigo, foi de preferência utilizar o termo geossítio para denominar os elementos da geodiversidade.

Os geossítios são ocorrências de um ou mais elementos da geodiversidade resultantes de processos naturais ou de intervenções humanas, ocorrendo em uma área bem delimitada geograficamente e que apresente valor singular do ponto de vista científico, pedagógico, cultural, turístico entre outros (Brilha, 2005).

A inventariação constitui a primeira etapa para identificar e caracterizar os geossítios. A segunda etapa consiste na quantificação, que tem como objetivo estabelecer um conjunto de valores (notas) que são constituídos por parâmetros, e que são pontuados por meio de uma série de critérios e subcritérios. Em seguida são aplicadas equações matemáticas para calcular a nota final, possibilitando a comparação e a identificação do potencial de uso de cada elemento estudado (Sena, 2015).

Existem várias metodologias de quantificação como, por exemplo, o método de Rivas et al. (1997), Brilha (2005), Pralong (2005), Pereira (2006), García-Cortés e Urquí (2009) e Brilha (2015). Essas metodologias 
foram elaboradas para quantificar o patrimônio geológico europeu. No contexto nacional, temos os métodos de Lima (2008), Evangelista e Travassos (2014), Sena (2015) e Santos (2017), que são adaptações das metodologias europeias, onde cada pesquisador acrescenta, remove ou redistribui os critérios e valores de acordo com a realidade da área de estudo de modo a aperfeiçoar e alcançar seus objetivos.

A quantificação é um método fundamental para determinar o potencial de uso, e estabelecer medidas de conservação de acordo com o grau de vulnerabilidade e degradação. Uma vez que, a maior parte das ameaças a geodiversidade provém, direta ou indiretamente, de atividades humanas como, por exemplo, as atividades turísticas quando realizadas sem planejamento adequado (Brilha, 2005). Nesse sentido, para minimizar esse tipo de ameaça destacamos as estratégias de conservação da natureza, com destaque para aquelas focadas na geoconservação.

A geoconservação consiste na implementação de estratégias ou metodologias destinadas a avaliar, valorizar, divulgar e conservar os elementos da geodiversidade que possuam valor científico, educativo, turístico, entre outros. Tais estratégias são realizadas na seguinte sequência: inventariação, quantificação, classificação, conservação, valorização, divulgação e monitoramento (Brilha, 2005). Quando aplicadas corretamente, esses métodos podem conservar e minimizar a degradação da geodiversidade.

A geoconservação deve ser baseada em estratégias criteriosas e passar por medidas de sensibilização e, para isso, tem como aliado o geoturismo (Bento \& Rodrigues, 2010). Dessa forma, uma das consequências da geoconservação é a promoção do geoturismo, que também pode promover a geoconservação (Moreira, 2008).

O geoturismo tem como objetivo o aproveitamento turístico dos elementos abióticos como: as rochas, as cavidades, os solos e o relevo. Este segmento pode auxiliar na promoção, na divulgação e na valorização da geodiversidade, por meio da educação ambiental que utiliza de meios interpretativos para traduzir a linguagem científica para uma linguagem comum, fazendo com que os visitantes passem a contribuir com a conservação dos elementos da geodiversidade (Moreira, 2008).

Dentre as áreas mais utilizadas por este segmento merecem destaque aquelas que são protegidas por lei e para as quais as pessoas se deslocam seja para recreação, contemplação ou esporte. Assim sendo, essa pesquisa foi realizada no Parque Estadual Serra do Rola Moça (PESRM), unidade de conservação localizada na região metropolitana de Belo Horizonte (Minas Gerais). O PESRM é composto por uma rica associação entre biodiversidade, que inclui vários endemismos de fauna e flora, e da geodiversidade compreendendo elementos do geossistema ferruginoso do Quadrilátero Ferrífero, afloramentos rochosos, recursos hídricos, cavernas em rochas ferruginosas, feições geológicas e geomorfológicas.

Neste sentido, o presente artigo tem por objetivo identificar geossítios localizados no PESRM, realizando avaliação quantitativa e do risco de degradação com ênfase no uso turístico.

Este estudo foi realizado com a finalidade de auxiliar na gestão das políticas de uso público do PESRM, contribuindo para a divulgação, valorização e conservação da geodiversidade. Além de ser uma forma diferenciada para o visitante apreciar a natureza, e obter informações sobre a geodiversidade o que Ihe proporcionará uma visão holística da área visitada.

\section{CARACTERIZAÇÃO DA ÁREA DE ESTUDO}

O Parque Estadual Serra do Rola Moça (PESRM) é uma unidade de conservação da categoria de proteção integral, sendo permitido o uso indireto dos recursos naturais, por meio de visitação e pesquisas científicas. O PESRM possui uma área total de 3.942 hectares e foi criada em 27 de setembro de 1994, pelo Decreto Estadual $n^{\circ} 36.071$, com o objetivo de conservar os ecossistemas locais e proteger seis mananciais de água (Bálsamo, Barreiro, Catarina, Mutuca, Rola-Moça e Taboões) (Minas Gerais, 2007). O PESRM está localizado na Região Metropolitana de Belo Horizonte, abrangendo parte dos municípios de Belo Horizonte, Brumadinho, Ibirité e Nova Lima. Na Figura 1 é apresentado o mapa de localização do PESRM. 
Figura 1 - Localização do Parque Estadual Serra do Rola Moça/MG

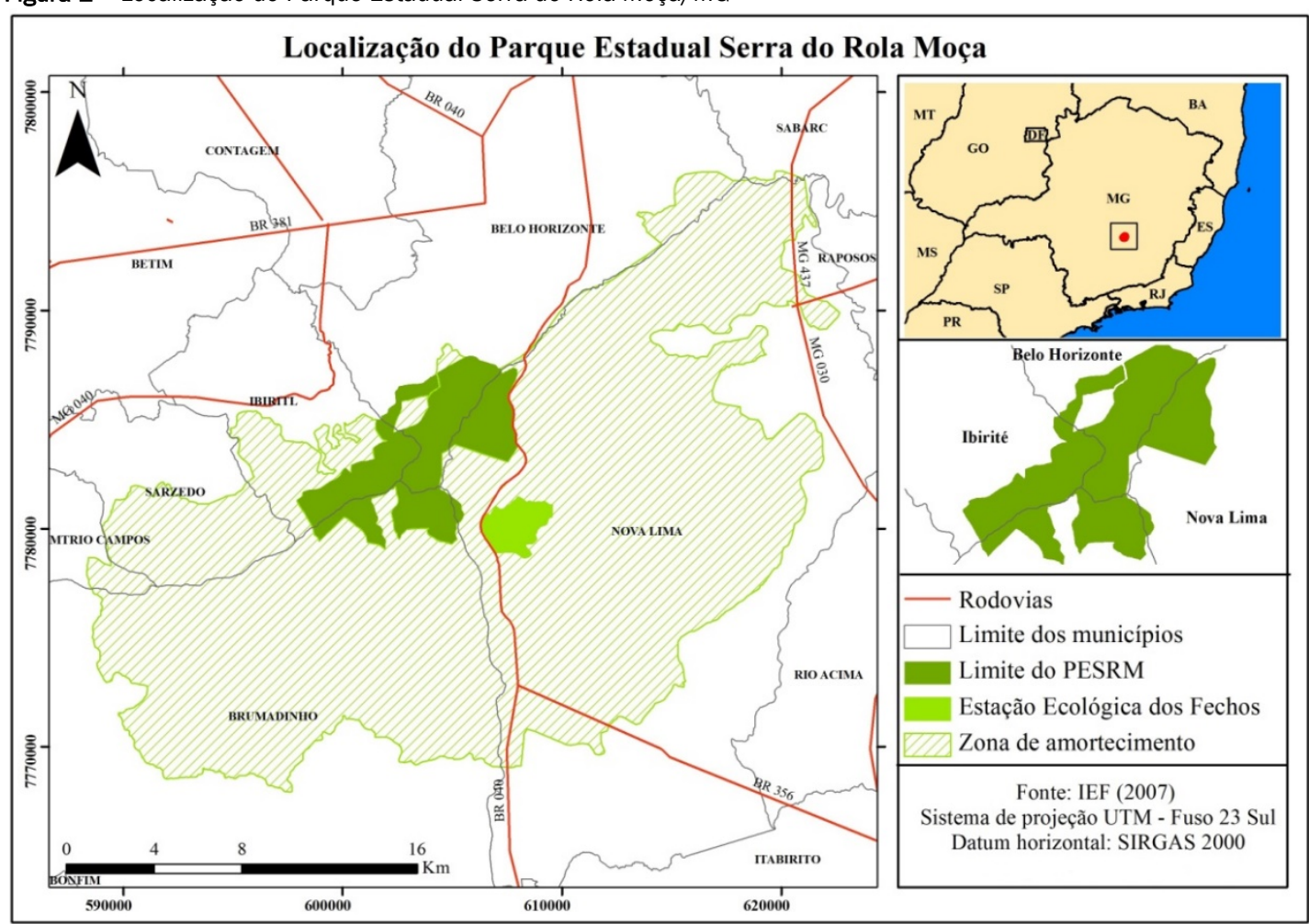

Fonte: Elaboração própria (2018).

O PESRM possui o programa de visitação e uso público, que foi subdividido em três categorias sendo: uso turístico, uso técnico e uso científico, que estão sobre administração do Instituto Estadual de Floresta de Minas Gerais (IEF/MG).

O uso turístico é composto por atividades recreativas e de educação ambiental. 0 uso técnico ocorre em áreas de fragilidade do PESRM, e devido a esse motivo recebe somente visitantes especializados (biólogos, geólogos, paleontólogos, etc.). E por fim, o uso científico é permitido somente para pesquisadores, pois ocorre em áreas de extrema fragilidade, sendo proibido para o uso turístico e técnico (MINAS GERAIS, 2007).

Para o uso turístico o PESRM possui três trilhas interpretativas sendo: trilha Travessia, Campo Ferruginoso e Morro III. Ao longo das trilhas é possível encontrar atrativos como mirantes, grutas, mananciais e cachoeiras. São permitidas atividades como caminhadas, ciclismo e esportes (MINAS GERAIS, 2007).

As atividades de educação ambiental propostas no uso público do PESRM estão ligadas a apreciação e conservação do meio ambiente. No PESRM existe um painel interpretativo localizado no Mirante dos Veados que contém resumidamente informações sobre a geodiversidade presente na área de estudo, porém, o painel se encontra danificado com a presença de pichações.

Portanto, a inclusão do geoturismo nas atividades de uso público do PESRM, se bem planejado, pode resultar na conscientização dos visitantes sobre a importância de se conservar os elementos da geodiversidade.

\section{METODOLOGIA}

Para a realização da avaliação quantitativa e do risco de degradação dos geossítios do PESRM, foram realizados os seguintes procedimentos metodológicos, descritos a seguir.

\subsection{Revisão bibliográfica}

Para alcançar os objetivos desta pesquisa, no primeiro momento, foi realizada a revisão e análise das teorias relacionadas ao objeto de estudo. Os procedimentos utilizados consistiram em pesquisa bibliográfica, sendo 
utilizados como fontes: livros, artigos e dissertações que abordavam temas sobre geodiversidade e geoturismo. Nesse sentido, para a avaliação quantitativa e do risco de degradação dos geossítios, foi utilizada a metodologia proposta por Brilha (2015), que foi adaptada com o objetivo de adequar a realidade da área de estudo.

É importante fazer uma ressalva, pois Brilha (2015) reformulou seu conceito de geossítio. Para o autor a geodiversidade é dividida em dois grandes grupos: sítios com valor científico e sítios com outros valores, ambos in situ ou ex situ. Sendo assim, os geossítios são compostos por elementos da geodiversidade in situ, que possuem alto valor científico, constituindo o patrimônio geológico. Já os sítios de geodiversidade são compostos pelas feições e pelos processos naturais da geodiversidade, que se destacam devido ao alto valor didático ou turístico. Da mesma forma que os geossítios, esses são constituídos por ocorrências in situ.

Porém, o patrimônio natural é constituído por formações físicas e biológicas ou por grupos de tais formações com valor universal excepcional do ponto de vista estético, turístico, científico entre outros. Neste caso, considera-se uma perda de apropriação do termo geossítio apenas em locais de importância científica (Meira \& Morais, 2016). Como esta pesquisa foca na análise turística adaptou-se a metodologia de Brilha (2015), entretanto não foi utilizado o termo "sítio de geodiversidade" como sugerido por Brilha (2015), mas foi utilizado o termo "geossítio".

\subsection{Identificação dos geossítios}

Para a identificação dos potenciais geossítios foram realizadas pesquisas bibliográficas, sendo utilizado como fonte: o plano de manejo do PESRM (2007). Dessa forma, foram considerados todos os recursos naturais de base abiótica, abertos atualmente à visitação. Em seguida, foi efetuada uma consulta aos especialistas do Centro Nacional de Pesquisa e Conservação de Cavernas (CECAV), que trabalham no PESRM, para identificação de possíveis cavernas que apresentassem condições para constituir geossítios para o uso turístico.

\subsection{Avaliação qualitativa}

Após a identificação dos geossítios, foram realizados dois trabalhos de campo para avaliação qualitativa dos sítios com potencial de uso turístico, por meio de uma ficha de caracterização proposta por Brilha (2015). Este autor sugere que a avaliação seja feita com base nos parâmetros referentes ao cenário, potencial interpretativo, acessibilidade e segurança, esses parâmetros podem ser compreendidos como:

- Cenário: está associado à beleza dos elementos da geodiversidade;

- Potencial interpretativo: está relacionado à capacidade de um elemento da geodiversidade ser facilmente compreendido por leigos;

- Acessibilidade: está associado às condições de acesso (estradas ou trilhas), considerando as dificuldades e o tempo para se chegar ao sítio;

- Segurança: está relacionado às condições de visita ao sítio, considerando-se o menor risco para as pessoas que o acessam.

Os geossítios com alto potencial de uso turístico, segundo Brilha (2015), serão aqueles que apresentarem grande beleza cênica, elementos da geodiversidade que possam ser facilmente observados e compreendidos por leigos e ter boas condições de segurança e acesso rápido.

\subsection{Quantificação dos geossítios}

Após a identificação e o preenchimento das fichas de caracterização dos geossítios, foi realizada avaliação quantitativa, dando-se início ao processo de atribuição de notas para cada sítio. Os critérios utilizados foram adaptados do trabalho de Brilha (2015), que apresenta uma proposta de quantificação baseada em três fatores: Potencial de Uso Didático (PUD), Potencial de Uso Turístico (PUT) e Risco de Degradação (RD).

Cada um dos critérios foi subdividido em quatro subcritérios que foram pontuados de 1 a 4 , sendo que, para o PUD e PUT, a nota 1 corresponde a baixa possibilidade de uso e a nota 4 corresponde a alta possibilidade 
de uso. A quantificação de Brilha (2015) foi pensada e elaborada para o uso didático e turístico, mas como esse trabalho tem como foco o uso turístico, optou-se em não utilizar os critérios do PUD. E para o PUT foram realizadas algumas adaptações nos critérios proposto por Brilha (2015), levando em consideração a escala da área de estudo.

Brilha (2015) propõe 13 critérios para a avaliação quantitativa do PUT, destes, apenas o critério densidade populacional que não foi utilizado. Este critério foi retirado da avaliação, pois foi considerado irrelevante para a área de estudo devido à escala de análise.

O critério logístico foi dividido em duas partes sendo: segmentos de hospedagem e segmentos de alimentação. Estes dois critérios foram divididos para facilitar na avaliação quantitativa e espacial dos sítios. Para análise desses dois itens, primeiramente, foi realizado o levantamento de todos os segmentos de hospedagem e alimentação dos municípios de Brumadinho, Ibirité e Nova Lima, por meio do Inventário da Oferta Turística (INVITUR). O INVITUR foi disponibilizado pela Secretaria de Estado de Turismo de Minas Gerais (SETUR-MG). 0 município de Belo Horizonte não possui inventário, dessa forma, os registros dos serviços de hospedagem foram obtidos na Secretaria Municipal Adjunta de Regulação Urbana (SMARU). Os serviços de alimentação foram adquiridos no site da Empresa Municipal de Turismo de Belo Horizonte (BELOTUR).

Em posse dos dados, estes foram analisados espacialmente com base no conceito elaborado por Boullón (2002) de corredores turísticos de translado, que são vias de conexão entre zonas, áreas e atrativos. Para Boullón (2002), é importante que os equipamentos turísticos, como posto de gasolina, hotéis, restaurantes, dentre outros, estejam nos corredores de translado. Ainda segundo o autor existe um raio de influência de $3 \mathrm{~km}$ entre os atrativos turísticos e os corredores de translado. Dessa forma, para quantificação destes dois critérios, foram analisadas as distâncias dos sítios aos segmentos de hospedagem e alimentação, utilizando a ferramenta Point Distance do software AcrGIS 10.3. Na Tabela 1 são apresentados os critérios e as notas da quantificação adaptada de Brilha (2015).

Tabela 1 - Critérios para avaliação quantitativa do potencial de uso turístico

(continua)

\section{Potencial de Uso Turístico (PUT)}

Critérios/Indicadores

Notas

\section{A. Vulnerabilidade}

Os elementos da geodiversidade do geossítio não apresentam possibilidade de deterioração por atividade turística.

Existe a possibilidade de deterioração de elementos da geodiversidade secundários pela atividade turística.

Existe a possibilidade de deterioração dos principais elementos da geodiversidade pela atividade turística.

Existe a possibilidade de deterioração de todos os elementos da geodiversidade pela atividade turística.

\section{B. Acessibilidade}

Geossítio localizado a menos de 100 metros de uma estrada acessível para veículos do tipo passeio. Geossítio localizado a menos de 300 metros de uma estrada acessível para veículos do tipo passeio. Geossítio localizado a menos de 100 metros de uma estrada acessível por veículo 4x4. Geossítio sem acesso direto por estrada, sendo necessário caminhar em trilhas.

C. Limitações de uso

O geossítio não tem limitações de uso para turistas e estudantes.

O geossítio pode ser usado por estudantes e turistas, mas apenas ocasionalmente.

O geossítio pode ser usado por estudantes e turistas, mas somente após superar algumas limitações (legal, geográfica, meteorológica, etc.).

O uso por estudantes e turistas é difícil de alcançar devido às dificuldades das limitações (legal, geográfica, meteorológica, etc.).

\section{Segurança}

Geossítio com estrutura de segurança (cercas, escadas, corrimãos, etc.), cobertura de telefonia celular e localizado a menos de $5 \mathrm{~km}$ de serviços de emergência.

Geossítio com estrutura de segurança (cercas, escadas, corrimãos, etc.), cobertura de telefonia celular e localizado a menos de $25 \mathrm{~km}$ de serviços de emergência.

Geossítio sem estrutura de segurança, mas com cobertura de telefonia celular e localizado a menos de $50 \mathrm{~km}$ de serviços de emergência. 
Geossítio sem estrutura de segurança, sem cobertura de telefonia celular e localizado a mais de 50

$\mathrm{km}$ de serviço de emergência.

\section{E. Segmentos de hospedagem}

Ocorre três ou mais segmentos de hospedagem a menos de $5 \mathrm{~km}$.

Ocorre um ou mais segmentos de hospedagem a menos de $10 \mathrm{~km}$.

Ocorre um ou mais segmentos de hospedagem a menos de $20 \mathrm{~km}$.

Ocorre um ou mais segmentos de hospedagem a menos de $30 \mathrm{~km}$.

\section{F. Segmentos de alimentação}

Ocorre três ou mais segmentos de alimentação a menos de $5 \mathrm{~km}$.

Ocorre um ou mais segmentos de alimentação a menos de $10 \mathrm{~km}$.

Ocorre um ou mais segmentos de alimentação a menos de $20 \mathrm{~km}$.

Ocorre um ou mais segmentos de alimentação a menos de $30 \mathrm{~km}$.

\section{G. Singularidade}

O geossítio apresenta características únicas e incomuns num contexto nacional e internacional.

O geossítio apresenta características únicas e incomuns num contexto nacional.

O geossítio apresenta características comuns num contexto regional e incomuns no contexto de outras regiões do país.

O geossítio apresenta características bastante comuns em todo o país.

\section{H. Associação com outros valores}

Ocorre a presença de três valores ecológicos e culturais, próximo ao geossítio analisado.

Ocorre a presença de dois valores ecológicos e culturais, próximo ao geossítio analisado.

Ocorre a presença de um valor ecológico e um valor cultural, próximo ao geossítio analisado.

Ocorre a presença de um valor ecológico ou cultural, próximo ao geossítio analisado.

\section{Cenário}

Geossítio apresenta condições para visualização da paisagem onde está inserido e da paisagem de seu entorno, inclusive da inserção de outros geossítios.

Geossítio apresenta condições para visualização da paisagem onde está inserido e da paisagem de seu entorno.

Geossítio apresenta condições para visualização da paisagem onde está inserido.

Geossítio com baixa visibilidade da paisagem.

\section{J. Condições de observação}

Todos os elementos da geodiversidade apresentam boas condições de observação.

Existem alguns obstáculos que dificultam a observação de alguns elementos da geodiversidade.

Existem alguns obstáculos que dificultam a observação dos principais elementos da geodiversidade.

Existem alguns obstáculos que obstruem a observação dos principais elementos da geodiversidade.

\section{K. Potencial interpretativo}

O geossítio apresenta elementos da geodiversidade de uma forma clara e expressiva para todos os tipos de público.

O público necessita de um conhecimento básico para compreender os elementos da geodiversidade do geossítio.

O público necessita de um conhecimento sólido para compreender os elementos da geodiversidade do geossítio.

O geossítio apresenta elementos da geodiversidade compreensíveis apenas por especialistas.

\section{Nível Econômico}

Geossítio localizado em um município com renda familiar superior a três salários mínimos.

Geossítio localizado em um município com renda familiar de três salários mínimos.

Geossítio localizado em um município com renda familiar de dois salários mínimos.

Geossítio localizado em um município com renda familiar de um salário mínimo.

4

3

\section{Proximidade a outros geossítios}

Ocorre a presença de três ou mais geossítios em um raio de $1 \mathrm{~km}$, além do geossítio analisado.

Ocorre a presença de dois geossítios em um raio de $1 \mathrm{~km}$, além do geossítio analisado.

Ocorre a presença de um ou mais geossítios em um raio de $2 \mathrm{~km}$, além do geossítio analisado.

Ocorre a presença de um ou mais geossítios em um raio de $3 \mathrm{~km}$, além do geossítio analisado. Fonte: Adaptado de Brilha (2015).

É importante destacar que os critérios e subcritérios utilizados nesta pesquisa são de caráter subjetivo, ou seja, foram adequados de acordo com as especificidades da área de estudo.

Para cada um dos critérios da quantificação, foram atribuídos pesos, de acordo com sua importância para analisar o potencial de uso turístico, dessa forma, deu-se início a segunda etapa do processo de quantificação dos sítios que constituiu na ponderação dos critérios. Em decorrência das adaptações realizadas na avaliação quantitativa dos geossítios, o peso atribuído ao critério densidade populacional foi redirecionado 
para o critério logístico que foi dividido em duas partes (segmentos de hospedagem e segmentos de alimentação). Os demais pesos foram mantidos conforme Brilha (2015), e são apresentados na Tabela 2.

Tabela 2- Critérios do potencial de uso turístico e seus respectivos pesos.

\begin{tabular}{lc}
\hline Critérios & Potencial de Uso Turístico (PUT) \\
\hline A. Vulnerabilidade & Pesos \\
B. Acessibilidade & 10 \\
C. Limitações de uso & 10 \\
D. Segurança & 5 \\
E. Segmentos de hospedagem & 10 \\
F. Segmentos de alimentação & 5 \\
G. Singularidade & 5 \\
H. Associação com outros valores & 5 \\
I. Cenário & 5 \\
J. Condições de observação & 15 \\
K. Potencial interpretativo & 5 \\
L. Nível Econômico & 10 \\
M. Proximidade a outros geossítios & 5 \\
Total & 10 \\
\hline Fonte: Adaptado de Brilha (2015) & 100 \\
\hline
\end{tabular}

Fonte: Adaptado de Brilha (2015)

Quanto à indicação dos sítios com maior potencial para o uso turístico, utilizou-se a classificação empregada por Lima (2008), sendo estabelecidas três classes para a área de estudo: 100 - 200 correspondem aos sítios de baixo potencial turístico, 201 - 300 sítios de médio potencial e 301 - 400 sítios com alto potencial turístico.

\subsection{Quantificação do risco de degradação}

Para a avaliação e quantificação do risco de degradação (RD), Brilha (2015) propõe cinco critérios: deterioração dos elementos geológicos, proximidade a áreas/atividades com potencial causa de degradação, proteção legal, acessibilidade e densidade populacional.

Cada um destes critérios foi subdividido em quatro subcritérios que receberam notas que variam de 1 a 4 , e quanto menor a nota atribuída menor é o risco de degradação, e quanto maior a nota atribuída maior é o risco de degradação dos geossítios. Para este trabalho, o critério densidade populacional não foi utilizado, sendo considerado irrelevante para a área de estudo devido à escala de análise. Nos critérios deterioração dos elementos geológicos e acessibilidade foram realizadas algumas adaptações nos indicadores (subcritérios), para melhor adequação à realidade da área de estudo.

O critério deterioração dos elementos geológicos passou por um ajuste conceitual, sendo que, foi trocado o termo "elementos geológicos", pelo termo "elementos da geodiversidade", onde se inserem também as feições geológicas, geomorfológicas, entre outros. Nesse item, Brilha (2015) analisa a vulnerabilidade dos sítios a partir das características intrínsecas e das ações antrópicas.

O critério acessibilidade foi analisado por Brilha (2015), considerando que um sítio que tenha um fácil acesso é mais provável de ser danificado por uso indevido dos visitantes do que um com difícil acesso. Portanto, a acessibilidade foi avaliada por meio das distâncias entre os geossítios e as estradas pavimentadas e não pavimentadas, sendo que, quanto menor a distância entre o sítio e a estrada, maior foi a nota atribuída e, consequentemente, maior será o risco de degradação, e quanto maior a distância, menor foi a nota atribuída, assim, o risco de degradação será menor. Na Tabela 3 são apresentados os critérios e os indicadores utilizados no risco de degradação. 
Tabela 3 - Critérios para a avaliação do risco de degradação

\begin{tabular}{lc}
\hline \multicolumn{1}{c}{ Risco de Degradação (RD) } & Notas \\
Critérios/Indicadores & 4 \\
\hline A. Deterioração dos elementos da geodiversidade & 3 \\
Geossítio localizado em áreas com grau de vulnerabilidade muito alto e alto. & 2 \\
Geossítio localizado em áreas com grau de vulnerabilidade médio. & 1 \\
Geossítio localizado em áreas com grau de vulnerabilidade baixo. & 4 \\
Geossítio localizado em áreas com grau de vulnerabilidade muito baixo. & 3 \\
B. Proximidade a áreas/atividades com potencial causa de degradação & 2 \\
Geossítio localizado a menos de 50 metros de área/atividade com potencial causa de degradação. \\
Geossítio localizado a menos de 200 metros de área/atividade com potencial causa de degradação. \\
Geossítio localizado a menos de 500 metros de área/atividade com potencial causa de degradação. \\
Geossítio localizado a menos de 1000 metros de área/atividade com potencial causa de degrada- \\
ção. & 1 \\
C. Proteção legal & 4 \\
Geossítio localizado em área sem proteção legal e sem controle de acesso. & 3 \\
Geossítio localizado em área sem proteção legal, mas com controle de acesso. & 2 \\
Geossítio localizado em área com proteção legal, mas sem controle de acesso. & 1 \\
Geossítio localizado em área com proteção legal e controle de acesso. & 4 \\
D. Acessibilidade & 3 \\
Geossítio localizado a menos de 100 metros de uma estrada acessível para veículos do tipo passeio. \\
Geossítio localizado a menos de 300 metros de uma estrada acessível para veículos do tipo passeio. \\
Geossítio localizado a menos de 100 metros de uma estrada acessível por veículo 4x4. \\
Geossítio sem acesso direto por estrada, sendo necessário caminhar em trilhas. \\
\hline Fonte: Adaptado de Brilha (2015)
\end{tabular}

Fonte: Adaptado de Brilha (2015)

Para cada um dos critérios foram atribuídos pesos de acordo com sua importância para analisar o risco de degradação dos geossítios, sendo assim, essa etapa constituiu na ponderação dos critérios. Em decorrência das adaptações realizadas na avaliação do risco de degradação dos geossítios, o peso atribuído ao critério densidade populacional foi redirecionado para o critério deterioração dos elementos da geodiversidade, que passou a possuir peso total 45. Os demais pesos foram mantidos conforme Brilha (2015), e são apresentados na Tabela 4.

Tabela 4 - Critérios do risco de degradação e seus respectivos pesos

\begin{tabular}{lc}
\hline \multicolumn{1}{c}{ Risco de Degradação } & Pesos \\
\hline A. Deterios & 45 \\
B. Proximimação dos elementos da geodiversidade & 20 \\
C. Proteção Legal & 20 \\
D. Acessibilidade & 15 \\
Total & 100
\end{tabular}

Fonte: Adaptado de Brilha (2015)

A partir da ponderação dos critérios foi possível classificar se os geossítios possuem baixo, médio ou alto risco de degradação, conforme classificação elaborada por Brilha (2015), que é apresentada na Tabela 5.

Tabela 5 - Classificação do risco de degradação

\begin{tabular}{cc}
\hline Peso total & Risco de degradação \\
\hline$<200$ & Baixo \\
$201-300$ & Médio \\
$301-400$ & Alto \\
\hline
\end{tabular}

Fonte: Brilha (2015)

\section{RESULTADO E DISCUSSÕES}

\subsection{Avaliação quantitativa}

Foram identificados nove geossítios com vistas ao uso turístico: Cachoeira das Pitangueiras, Caverna RM03, Caverna RM-23, Mirante Casa Branca, Mirante Estrada Velha, Mirante Jatobá, Mirante Morro dos Veados, Mirante Planeta e Mirante Três Pedras. Na Figura 2 é apresentada a localização dos geossítios no PESRM. 
Figura 2- Mapa de localização dos geossítios

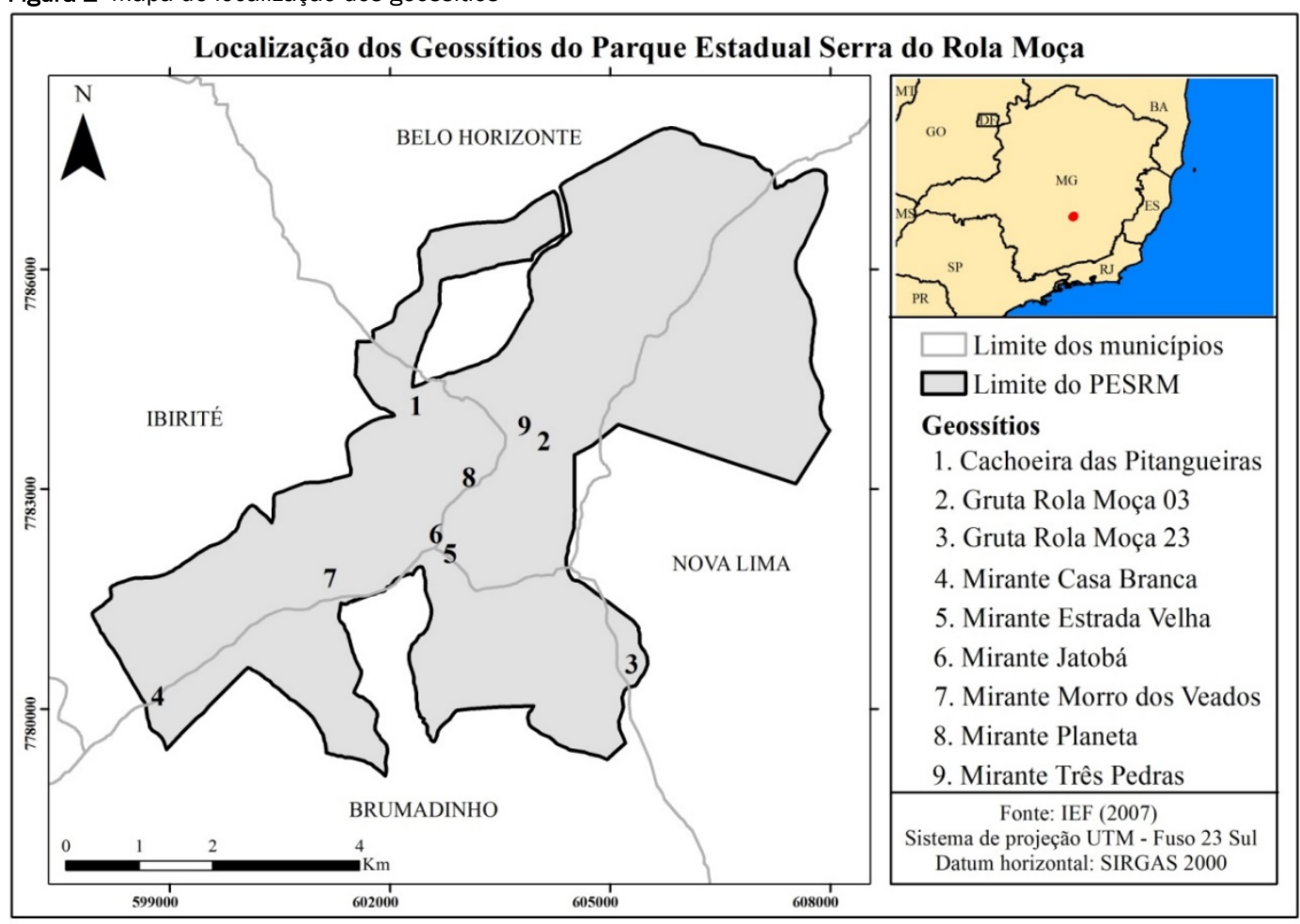

Fonte: Elaboração própria (2018)

Os geossítios Mirante Casa Branca, Mirante Estrada Velha e Mirante Jatobá foram identificados a partir de levantamento bibliográfico de trabalhos científicos publicados sobre o PESRM. Os geossítios Caverna RM-03 e Caverna RM-23 foram sugeridos por especialistas do Centro Nacional de Pesquisa e Conservação de Cavernas (CECAV), que trabalham no PESRM. E os geossítios Cachoeira das Pitangueiras, Mirante Morro dos Veados, Mirante Planeta e Mirante Três Pedras, constituem atrativos turísticos já utilizados pelos visitantes do PESRM. Na Figura 3 são apresentados ilustrações dos geossítios.

Por meio da avaliação quantitativa dos geossítios, foram obtidos os valores do potencial de uso turístico, situando-se entre 245 a 310. Os geossítios que obtiveram classificação média foram: Cachoeira das Pitangueiras, Caverna RM-03, Caverna RM-23, Mirante Casa Branca e Mirante Estrada Velha. E os geossítios que obtiveram classificação alta foram: os Mirantes Jatobá, Morro dos Veados, Planeta e três Pedras. Dessa forma, é exposto um breve esclarecimento sobre as notas atribuídas aos geossítios de acordo com cada critério.

$\mathrm{Na}$ avaliação do critério vulnerabilidade (A) foram considerados apenas os danos que são causados aos sítios em consequência do uso e não foram consideradas as ações intencionais para quebrar ou danificar os elementos da geodiversidade (Santos, 2017). Sendo assim, levando em conta os cenários atuais de uso e visitação do PESRM, os nove sítios receberam nota 4, pois durante o preenchimento da ficha de caracterização constatou-se que estes não apresentam risco de degradação por atividades turísticas.

Na avaliação da acessibilidade (B), os sítios Mirantes Casa Branca, Jatobá, Morro dos Veados, Planeta e Três Pedras receberam a nota máxima (4). Estes geossítios se encontram a menos de cem metros de uma estrada pavimentada ou não pavimentada que estão em boas condições de uso, sendo possível transitar com veículos de passeio o que facilita a visitação dos sítios. A Cachoeira das Pitangueiras e a Caverna RM-23 receberam nota 2, pois são acessíveis somente com veículo de tração nas quatro rodas. A Caverna RM-03 e o Mirante Estrada Velha receberam nota 1, pois são acessados por meio de trilha.

Para a avaliação do critério limitações de uso (C) foram considerados que todos os sítios poderão ser utilizados para fins turísticos, não existindo limitações legais, portanto receberam pontuação 4 . A Caverna RM-03 por possuir trechos difíceis de ser percorridos e demandar grande esforço físico, recebeu nota 2.

$\mathrm{Na}$ avaliação do critério segurança (D) foram medidas as distâncias entre cada sítio e os serviços de saúde. Sendo que dos nove sítios quantificados, oito receberam nota 2, pois não possuem nenhum tipo de estrutura de segurança e estão localizados a menos de cinquenta quilômetros de um serviço de emergência, mas possui cobertura de telefonia celular. Já a Cachoeira das Pitangueiras recebeu nota 3, uma vez que possui 
estrutura de segurança, como corrimão e escada, tem cobertura de telefonia celular e está localizado a menos de vinte e cinco quilômetros de um serviço de emergência.
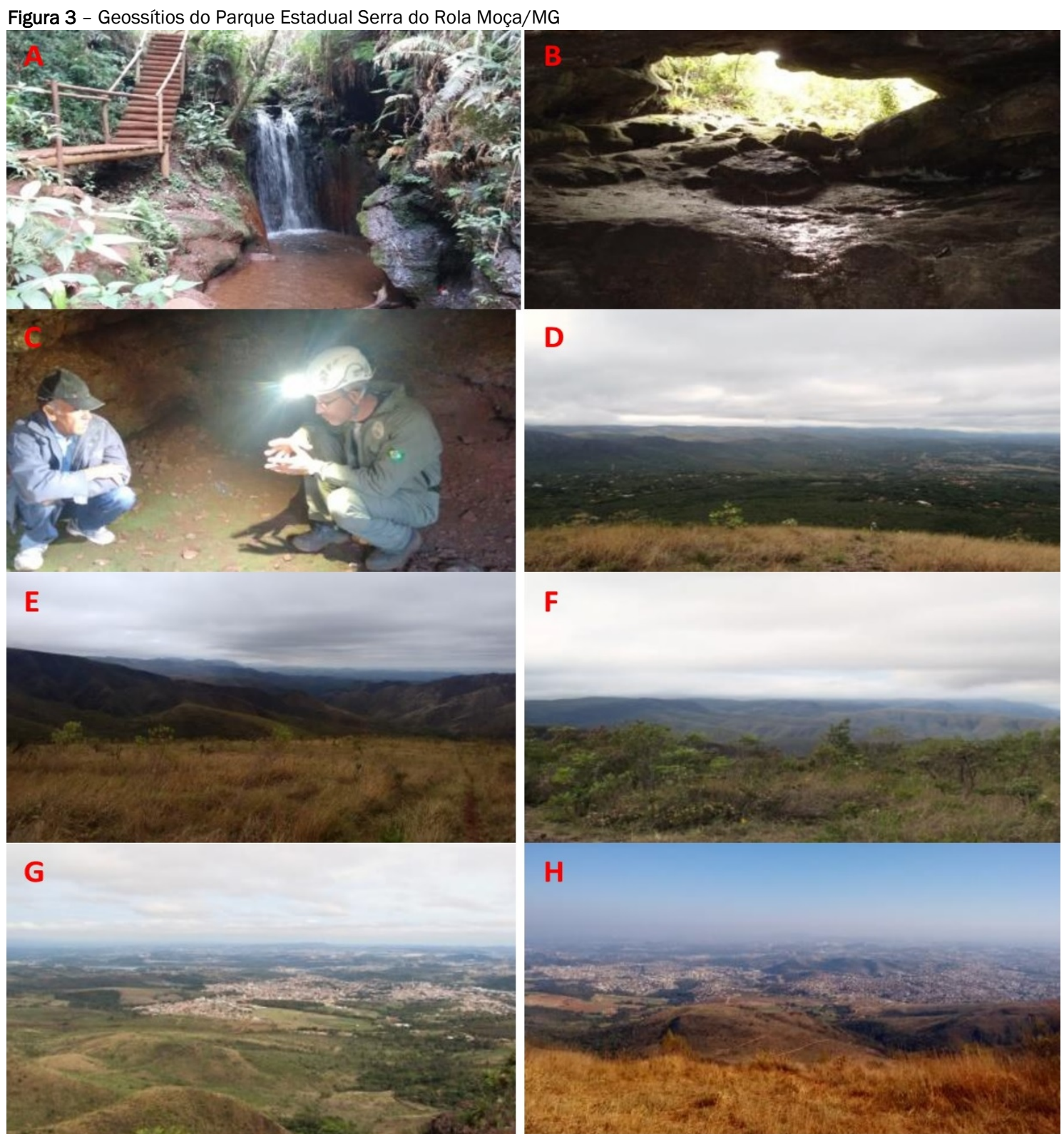

H

I

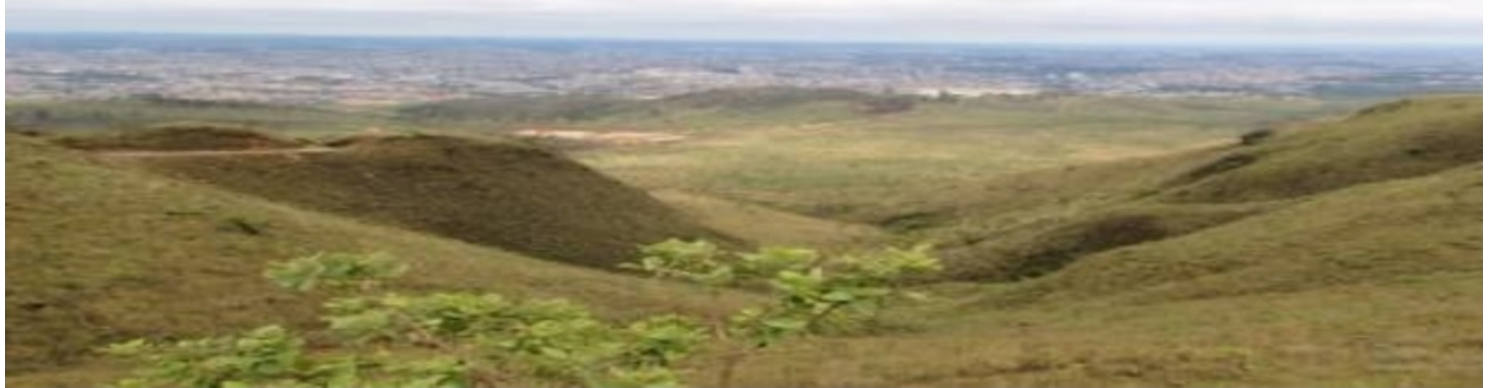

(A) Cachoeira das Pitangueiras; (B) Caverna RM-03; (C) Caverna RM-23; (D) Mirante Casa Branca; (E) Mirante Estrada Velha; (F) Mirante Jatobá; (G) Mirante Morro dos Veados; (H) Mirante Planeta; (I) Mirante Três Pedras.

Fonte: Arquivo pessoal (2018)

Nos critérios segmentos de hospedagem (E) e segmentos de alimentação (F), os geossítios receberam nota 4 ou 3. Esta pontuação alta ocorre devido ao fato de que esses critérios foram analisados com base no conceito de corredores turísticos de translado de Boullón (2002). Os sítios receberam essas notas, visto que 
se encontram localizados a menos de cinco (nota 4) ou dez (nota 3) quilômetros de um ou mais segmentos de hospedagem ou alimentação.

No critério singularidade $(G)$ todos os geossítios receberam nota 1, pois apresentam características que são bastante comuns em todo o país.

Na avaliação do critério associação com outros valores $(\mathrm{H})$ todos os sítios receberam nota 1, visto que próximos aos sítios não ocorrem a presença de valores culturais, ocorrendo apenas valores ecológicos e, normalmente, com a presença de um elemento.

No critério cenário (I) todos os seis mirantes receberam nota 3, pois apresentam condições para visualizar a paisagem onde está inserido e de seu entorno, entretanto não é possível visualizar outros geossítios. A Cachoeira das Pitangueiras e a Caverna RM-03 receberam nota 2, por apresentarem condições de visibilidade apenas da paisagem onde está inserido. E por último, a Caverna RM-23 foi o único sítio que recebeu nota 1, apresentando baixa visibilidade, porque está inserida em um local onde a vegetação é densa e prejudica a visualização do cenário.

$\mathrm{Na}$ avaliação do critério condições de observação $(\mathrm{J})$ todos os sítios receberam nota 4 , sendo que, durante os trabalhos de campo não foram encontrados nenhum tipo de obstáculos que dificultasse ou impedisse a observação dos elementos da geodiversidade que se encontram em bom estado de conservação.

No critério potencial interpretativo $(\mathrm{K})$, os sítios foram avaliados levando em consideração se os elementos da geodiversidade são facilmente compreendidos por todos os tipos de público. Durante os trabalhos de campo observou-se que os geossítios não apresentam elementos de grande complexidade, ou seja, não exige do visitante conhecimentos profundos sobre a geodiversidade, sendo assim, todos receberam nota 4 (quatro).

O critério nível econômico (L) refere-se ao nível de renda das famílias que residem próximos aos sítios. Este critério foi avaliado com base no salário médio mensal dos trabalhadores formais que moram nos municípios que fazem limite com o PESRM, conforme os dados do IBGE (2015). Os sítios que estão localizados em Belo Horizonte que tem uma média de 3,7 salários mínimos receberam nota 3, os sítios localizados em Brumadinho e Ibirité receberam nota 2, por apresentarem uma média de 2 salários mínimos.

Por último, no critério proximidade a outros geossítios (M) foi analisado que estes se encontram próximos, sendo que a menor distância ocorreu entre o Mirante Estrada Velha e o Mirante Jatobá (309 metros) e a maior ocorreu entre o Mirante Casa Branca e a Caverna RM-23 (6,4 km). Portanto, a proximidade entre os sítios pode facilitar e agilizar a visitação e o tempo disponível pelos visitantes.

A partir da quantificação observa-se que o potencial de uso turístico, apontou resultados representativos com valores da ponderação variando entre 245 a 310. Na Tabela 6 são apresentados os valores da quantificação do PUT.

Os sítios que apresentaram maior pontuação foram os mirantes que consistem nos locais de maior visitação do PESRM e possuem fácil acesso e são dotados de apelo cênico. A Cachoeira das Pitangueiras foi outro local com pontuação destacada. Apesar de ser acessada por veículos de tração nas quatro rodas, a cachoeira conta com estruturas de segurança (escada e corrimão) que contribuiu para uma média pontuação no PUT. Os sítios que obtiveram a menor pontuação foram a Caverna RM-03 (255) e a Caverna RM-23 (245) que, apesar de serem providas de um médio potencial turístico, não são alvos de visitação, pois estão situados em locais remotos. Assim sendo, é necessário que os gestores do PESRM elaborem ações de divulgação e melhoria na infraestrutura de acesso dessas cavernas, pois são locais propícios para abordar temas sobre os aspectos genéticos e sobre espeleotemas. 


\section{POTENCIAL DE USO TURÍSTICO}

\begin{tabular}{|c|c|c|c|c|c|c|c|c|c|c|c|c|c|c|c|c|c|c|c|c|c|c|c|c|c|c|c|c|}
\hline \multirow{2}{*}{ Sítios } & \multicolumn{13}{|c|}{ Valores absolutos } & \multicolumn{13}{|c|}{ Valores ponderados } & \multirow{2}{*}{ Total } & \multirow{2}{*}{$\begin{array}{l}\text { Classificação } \\
\text { Lima (2008) }\end{array}$} \\
\hline & $A$ & B & C & $\mathrm{D}$ & $\mathrm{E}$ & $\mathrm{F}$ & $\mathrm{G}$ & $\mathrm{H}$ & I & $J$ & K & $\mathrm{L}$ & M & A & B & $\mathrm{C}$ & $\mathrm{D}$ & $E$ & $\mathrm{~F}$ & G & $\mathrm{H}$ & I & $J$ & K & $\mathrm{L}$ & M & & \\
\hline $\begin{array}{l}\text { Cachoeira das } \\
\text { Pitangueiras }\end{array}$ & 4 & 2 & 4 & 3 & 3 & 4 & 1 & 1 & 2 & 4 & 4 & 2 & 4 & 40 & 20 & 20 & 30 & 15 & 20 & 20 & 5 & 30 & 20 & 40 & 10 & 40 & 280 & Médio \\
\hline Caverna RM-03 & 4 & 1 & 2 & 2 & 3 & 4 & 1 & 1 & 2 & 4 & 4 & 3 & 4 & 40 & 10 & 10 & 20 & 15 & 20 & 20 & 5 & 30 & 20 & 40 & 15 & 40 & 255 & Médio \\
\hline Caverna RM-23 & 4 & 2 & 4 & 2 & 3 & 4 & 1 & 1 & 1 & 4 & 4 & 2 & 2 & 40 & 20 & 20 & 20 & 15 & 20 & 10 & 5 & 15 & 20 & 40 & 10 & 20 & 245 & Médio \\
\hline $\begin{array}{c}\text { Mirante Casa } \\
\text { Branca }\end{array}$ & 4 & 4 & 4 & 2 & 4 & 4 & 1 & 1 & 3 & 4 & 4 & 2 & 2 & 40 & 40 & 20 & 20 & 20 & 20 & 10 & 5 & 45 & 20 & 40 & 10 & 20 & 300 & Médio \\
\hline $\begin{array}{l}\text { Mirante Estrada } \\
\text { Velha }\end{array}$ & 4 & 1 & 4 & 2 & 4 & 4 & 1 & 1 & 3 & 4 & 4 & 2 & 4 & 40 & 10 & 20 & 20 & 20 & 20 & 10 & 5 & 45 & 20 & 40 & 10 & 40 & 280 & Médio \\
\hline Mirante Jatobá & 4 & 4 & 4 & 2 & 4 & 4 & 1 & 1 & 3 & 4 & 4 & 2 & 4 & 40 & 40 & 20 & 20 & 20 & 20 & 10 & 5 & 45 & 20 & 40 & 10 & 40 & 310 & Alto \\
\hline $\begin{array}{c}\text { Mirante Morro dos } \\
\text { Veados }\end{array}$ & 4 & 4 & 4 & 2 & 4 & 4 & 1 & 1 & 3 & 4 & 4 & 2 & 3 & 40 & 40 & 20 & 20 & 20 & 20 & 20 & 5 & 45 & 20 & 40 & 10 & 30 & 305 & Alto \\
\hline Mirante Planeta & 4 & 4 & 4 & 2 & 3 & 4 & 1 & 1 & 3 & 4 & 4 & 3 & 4 & 40 & 40 & 20 & 20 & 15 & 20 & 20 & 5 & 45 & 20 & 40 & 15 & 40 & 310 & Alto \\
\hline Mirante Três Pedras & 4 & 4 & 4 & 2 & 3 & 4 & 1 & 1 & 3 & 4 & 4 & 3 & 4 & 40 & 40 & 20 & 20 & 15 & 20 & 20 & 5 & 45 & 20 & 40 & 15 & 40 & 310 & Alto \\
\hline
\end{tabular}

Fonte: Elaboração própria (2018) 


\subsection{Risco de degradação}

Os valores obtidos na quantificação do risco de degradação variam de 180 a 300. Os sítios foram avaliados em relação às ameaças antrópicas e naturais. No Tabela 7 são apresentados os valores absolutos e ponderados dos sítios.

Tabela 7 - Avaliação do risco de degradação dos geossítios

\begin{tabular}{|c|c|c|c|c|c|c|c|c|c|c|}
\hline \multirow{3}{*}{ Sítios } & \multicolumn{8}{|c|}{ Risco de Degradação } & \multirow{3}{*}{ Total } & \multirow{3}{*}{$\begin{array}{l}\text { Classificação } \\
\text { Brilha (2015) }\end{array}$} \\
\hline & \multicolumn{4}{|c|}{ Valores absolutos } & \multicolumn{4}{|c|}{ Valores ponderados } & & \\
\hline & A & B & $\mathrm{C}$ & D & A & B & $\mathrm{C}$ & D & & \\
\hline $\begin{array}{l}\text { Cachoeira das } \\
\text { Pitangueiras }\end{array}$ & 2 & 1 & 2 & 2 & 90 & 20 & 40 & 30 & 180 & Baixo \\
\hline Caverna RM-03 & 4 & 1 & 2 & 1 & 180 & 20 & 40 & 15 & 255 & Médio \\
\hline Caverna RM-23 & 3 & 2 & 2 & 2 & 135 & 40 & 40 & 30 & 245 & Médio \\
\hline Mirante Casa Branca & 4 & 1 & 2 & 4 & 180 & 20 & 40 & 60 & 300 & Médio \\
\hline Mirante Estrada Velha & 4 & 1 & 2 & 1 & 180 & 20 & 40 & 15 & 225 & Médio \\
\hline Mirante Jatobá & 4 & 1 & 2 & 4 & 180 & 20 & 40 & 60 & 300 & Médio \\
\hline $\begin{array}{c}\text { Mirante Morro dos Vea- } \\
\text { dos }\end{array}$ & 4 & 1 & 2 & 4 & 180 & 20 & 40 & 60 & 300 & Médio \\
\hline Mirante Planeta & 4 & 1 & 2 & 4 & 180 & 20 & 40 & 60 & 300 & Médio \\
\hline Mirante Três Pedras & 4 & 1 & 2 & 4 & 180 & 20 & 40 & 60 & 300 & Médio \\
\hline
\end{tabular}

A partir da Tabela 7 é possível observar que os geossítios apresentaram médio risco de degradação, com valores variando entre 255 a 300. Esse fator é resultado da localização desses sítios em áreas que apresentaram alto índice de vulnerabilidade ambiental (A), recebendo pontuação 4 ou 3, apenas a Cachoeira das Pitangueiras que recebeu menor pontuação, com a nota 2.

Outro fator que influenciou no resultado do médio risco de degradação foi o critério acessibilidade (D), os sítios Mirantes Casa Branca, Jatobá, Morro dos Veados, Planeta e Três Pedras receberam nota 4. Estes sítios encontram-se muito próximos as estradas pavimentadas e não pavimentadas que estão em boas condições de conservação, sendo possível transitar com veículos de passeio o que facilita o acesso dos visitantes e da população local e pode ocasionar em degradação pelo mau uso. A Cachoeira das Pitangueiras e a Caverna RM-23 receberam nota 2, pois são acessíveis apenas com veículos de tração nas quatro rodas. A Caverna RM-03 e o Mirante Estrada Velha receberam nota 1, pois o acesso a estes é feito por meio de trilha, o que pode ocasionar em uma menor degradação.

O critério proteção legal (C) não influenciou na quantificação do RD, pois os sítios se encontram em uma área legalmente protegida, mas não possui nenhum tipo de mecanismo de controle de acesso por parte da administração do PESRM. Dessa forma, todos os sítios receberam a mesma nota (2), tendo em vista que necessitam de conscientização e fiscalização sobre o seu uso.

$\mathrm{Na}$ avaliação do critério proximidade a áreas/atividades com potencial causa de degradação (B), como áreas de mineração, urbanas e indústrias, os geossítios receberam pontuação 1, pois estes encontram-se a mais de 1000 metros de algum tipo de atividade ou área que possa causar degradação.

Observa-se que dos noves geossítios analisados, oito apresentaram médio risco de degradação, portanto, é necessário que os gestores do PESRM definam ações para a manutenção dos sítios de acordo com o uso que os mesmos estão sendo submetidos, realizando avaliações periódicas da vulnerabilidade e conscientizando a população local e os visitantes sobre a importância da conservação dos sítios. 


\section{CONSIDERAÇÕES FINAIS}

A proposta desse estudo foi avaliar a geodiversidade do Parque Estadual Serra do Rola Moça com o objetivo de identificar geossítios com maior potencial para o uso turístico, para serem alvos de futuras atividades geoturísticas de caráter educativos e interpretativos. Desse modo, de acordo com os resultados apresentados, foi constatada que o PESRM apresenta grande riqueza geológica e geomorfológica a qual, na maioria das vezes, não é divulgada junto aos visitantes.

A quantificação dos geossítios indicou aqueles que apresentam melhores condições para o uso turístico, apresentando, entretanto, o caráter dinâmico dessa metodologia. Nesse sentido, ao usar metodologias de quantificação, o pesquisador precisa levar em consideração a realidade de cada área de estudo e os objetivos pretendidos. Isto porque mudanças em alguns dos critérios de análise poderão alterar o potencial de uso turístico dos sítios.

Outro ponto que deve ser considerado nessa pesquisa é em relação à identificação dos geossítios do PESRM, pois alguns locais não foram considerados na identificação realizada. 0 fator restritivo para a realização dessa etapa do trabalho está relacionado às limitações de acessos aos locais que estão sobre administração da Companhia de Saneamento de Minas Gerais (COPASA). O que impossibilitou a identificação e a quantificação de potenciais sítios localizados dentro dessas áreas. Em função disso, novos estudos sobre a geodiversidade do PESRM poderão ser realizados e novos sítios serão levantados, pois existem outros locais com potencial para o uso turístico, como é o caso do Abrigo Casa Branca, os Mananciais Catarina e Mutuca e a Serra das Andorinhas.

A identificação dos sítios realizada nessa pesquisa também não envolveu os elementos da geodiversidade contidos na Zona de Amortecimento do PESRM, sendo essa área de grande relevância em termos da geodiversidade. Possivelmente, trabalhos futuros poderão contemplar essa área e novos sítios serão identificados, portanto, faz-se necessário indicar para posterior levantamento: o Abrigo Retiro das Pedras, localizado no distrito de Piedade do Paraopeba, os Caminhos Antigos da Serra da Calçada, que constitui trechos de antigos caminhos do século XVIII, alguns com escoros de alvenaria de pedra, e o Forte Brumadinho.

Por fim, o PESRM apresenta uma rica geodiversidade e acredita-se que o desenvolvimento de atividades geoturísticas irá contribuir para o conhecimento, valorização e conservação da geodiversidade e da biodiversidade presente no PESRM, por meio de processos de interpretação promovidos pela educação ambiental. E para assegurar que tais atividades alcancem êxito, torna-se necessária a elaboração de estratégias em conjunto com a comunidade local, os gestores do PESRM, os visitantes e a comunidade acadêmica.

\section{REFERÊNCIAS}

Bento, L. C. M., \& Rodrigues, S. C. (2010). 0 geoturismo como instrumento em prol da divulgação, valorização e conservação do patrimônio natural abiótico - uma reflexão teórica. Turismo e Paisagens Cársticas, 3(2), $55-65$.

Boullón, R. C. (2002). Planejamento do espaço turístico. Bauru: EDUSC.

Brilha, J. (2015). Inventory and quantitative assessment of geosites and geodiversity sites: a review. Geoheritage, 8, 119-134. https://doi.org/10.1007/s12371-014-0139-3

(2005). Património geológico e geoconservação: a conservação da natureza na sua vertente geológica. Braga: Palimage.

Bruschi, V. M. (2007). Desarrollo de una metodología para La caracterización, evaluación y gestión de lós recursos de La geodiversidad. Tese (Doutorado em Ciencias de La Tierra y Fisica de La Materia Condensada). Universidad de Cantabria. Santander.

Evangelista, V. K., \& Travassos, L. E. P. (2014). Patrimônio geomorfológico do Parque Estadual do Sumidouro. Belo Horizonte: PUC Minas. 
Lima, F. F. (2008). Proposta metodológica para inventariação do patrimônio geológico brasileiro. Dissertação (Mestrado em Patrimônio Geológico e Conservação). Universidade do Minho. Braga.

MINAS GERAIS. (2007). Plano de manejo do Parque Estadual Serra do Rola Moça. Belo Horizonte. Disponível em: <http://www.ief.mg.gov.br/images/stories/Plano_de_Manejo/Rola_Moca/enc1_pesrm_eef-995.pdf>. Acesso em: 20 jun. 2018.

Meira, S. A., \& Morais, J. O. (2016). Os conceitos de geodiversidade, patrimônio geológico e geoconservação: abordagens sobre o papel da geografia no estudo da temática. Boletim de Geografia (Maringá), 34(3), 129147. https://doi.org/10.4025/bolgeogr.v34i3.29481

Moreira, J. C. (2008). Patrimônio geológico em unidades de conservação: atividades interpretativas, educativas e geoturísticas. Tese (Doutorado em Geografia). Universidade Federal de Santa Catarina. Florianópolis.

Pereira, P. J. S. (2006). Patrimônio geomorfológico: conceptualização, avaliação e divulgação. Aplicação ao Parque Natural Montesinho. Tese (Doutorado em Ciências). Universidade do Minho. Braga.

Romão, R. M. M., \& Garcia, M. G. M. (2017). Iniciativas de inventário e quantificação do patrimônio geológico no Brasil: panorama atual. Anuário do Instituto de Geociências (UFRJ), 40(2), $250-265$. https://doi.org/10.11137/201722 250265

Ruchkys, U. A. (2007). Patrimônio geológico e geoconservação no Quadrilátero Ferrírefo, Minas Gerais: potencial para a criação de um geoparque da UNESCO. Tese (Doutorado em Geologia). Universidade Federal de Minas Gerais. Belo Horizonte.

Santos, D. J. (2017). A geodiversidade do Parque Nacional da Serra do Gandarela: análise do potencial de uso didático com ênfase no patrimônio espeleológico. Dissertação (Mestrado em Análise e Modelagem de Sistemas Ambientais). Universidade Federal de Minas Gerais. Belo Horizonte.

Sena, I. S. (2015). Análise do potencial geoturístico da região central da área de proteção ambiental carste de Lagoa Santa - MG. Dissertação (Mestrado em Análise e Modelagem de Sistemas Ambientais). Universidade Federal de Minas Gerais. Belo Horizonte.

\section{Informações sobre a autora}

\section{Dayane Letícia Rodrigues dos Reis}

Mestre em Análise e Modelagem de Sistemas Ambientais pela UFMG (2018). Especialista em Geoprocessamento pela UFMG (2014). Graduada em Turismo pela UFMG (2012). Trabalha desenvolvendo pesquisa com ênfase em Cartografia Turística, Geoprocessamento, Modelagem Ambiental e Turismo.

Contribuição no texto: Desenvolvimento inicial da pesquisa; Revisão da literatura; Coleta de dados em campo; Análise e discussão dos dados; Revisão Final.

Email: dayanereis06@yahoo.com.br

ORCID: https://orcid.org/0000-0001-9619-1873 